\title{
Outcome of Pregnancy in Lupus
}

\author{
Syeda Sayeeda ${ }^{1}$, Firoza Begum ${ }^{2}$, Nahreen Akhtar ${ }^{3}$, Farzana Sharmin $^{4}$ \\ ${ }^{1}$ Assistant Professor, Fetomaternal Medicine wing, Department of Obs \& Gynae, BSMMU, ${ }^{2}$ Professor, Fetomaternal Medicine wing, \\ Department of Obs \& Gynae, BSMMU, ${ }^{3}$ Associate Professor, Fetomaternal Medicine Wing, Department of Obs \& Gynae, BSMMU, \\ ${ }^{4}$ Assistant Professor(C.C), Fetomaternal Medicine wing, Department of Obs \& Gynae, BSMMU.
}

\begin{abstract}
:
Background: Pregnancy in patients with SLE is associated with a high risk of maternal disease exacerbation in active disease state and adverse fetal outcome. Objective: To analyse maternal and fetal outcome in pregnant lupus patients as well as to identify influence of disease activity on it. Methods: This retrospective observational cross sectional study was done on 27 pregnant lupus patients in feto-maternal medicine wing of the department of Obstetrics and Gynaecology, BSMMU from April 2007 to March 2011. For statistical analysis ' $z$ ' test of proportion and student's ' $t$ ' test was used. Results: Mean age of the patients was 26.6 years. At booking, 8 (29.63\%) had active lupus while 19 (70.37\%) was in remission. As complications of SLE, lupus flare was found in $11.1 \%$, lupus nephritis in $25.9 \%$ and skin rash in $7.4 \%$. Regarding obstetric complications, PIH was developed in $3.7 \%$ and preeclampsia in $11.1 \%$ of the patients. Average gestational age at delivery was 34.8 weeks. Birth weight was $<2.5 \mathrm{~kg}$ in $45.8 \%$ of neonates. There was IUGR in $33.3 \%$ of the cases and $25 \%$ of the neonates needed admission in neonatal ICU. There was no neonatal death and none of the 24 neonates had neonatal lupus. In this study there was no maternal mortality. Patients who were in active disease state, most (55.5\%) delivered preterm, spontaneous abortion occurred in two and IUD in one of the patients. Average birth weight was lower $(1.9+.47 \mathrm{~kg})$ in patients with active SLE than those of with remission $(2.3+.68 \mathrm{~kg})$. Lupus flare developed in $66.6 \%$ with active disease, while in $33.3 \%$ with remission. Conclusion: Pregnancy is relatively safe with SLE in remission but considered as high risk in terms of fetal loss and spontaneous abortion. Disease activity influences pregnancy outcome.
\end{abstract}

Key words: Pregnancy outcome, disease activity, active lupus, lupus flare.

[BSMMU J 2012; 5(1):18-23]

\section{Introduction:}

Systemic Lupus Erythematosus (SLE) is an autoimmune rheumatic disease of unknown etiology. ${ }^{1}$ It is a rare disease that predominantly afflicts young woman of child bearing age. ${ }^{2}$ As a consequence pregnancy and its outcome are of particular importance in this condition. Although advances in the treatment of obstetric complications and improvement in neonatal medicine have allowed women with SLE to have successful pregnancies, SLE remains as a disease associated with significant fetal and maternal morbidity ${ }^{3}$.A variety of factors such as disease activity, renal involvement, a history of fetal loss, antiphospholipid antibodies, lymphotoxic antibodies and possibly antibodies to Ro (SSA) have been implicated in the pathogenesis of adverse pregnancy outcome in SLE patients. However the precise mechanism remains unknown. The literature is controversial regarding the frequency of lupus flare during pregnancy and the organ system in which flare occur. ${ }^{1}$

Address for Correspondence: Dr. Syeda Sayeeda, Assistant Professor, Fetomaternal Medicine wing, Department of Obs \& Gynae, BSMMU
The impact of pregnancy on lupus disease, especially with regard to incidence of disease exacerbation, was demonstrated by various studies and showed that lupus activity may increase ${ }^{34567}$, decrease or remain unchanged throughout pregnancy. $1,3,8,9,10,11,12$ Several reasons have been proposed to explain this disparity. Differences in the composition of patient cohorts and the use of nonstandardized definitions of lupus flare make comparison between studies difficult. Moreover, many complications common to pregnancy may be mistakenly attributed to $\mathrm{SLE}^{\cdot 3,11,14}$

In contrast, the impact of SLE on pregnancy is more clearly understood. Women with lupus disease are not less fertile, than unaffected women ${ }^{3,15}$, but fetal outcome in lupus pregnancy is characterized by higher rate of fetal loss, preterm delivery, intrauterine growth restriction (IUGR). ${ }^{3}$

Finally, SLE may affect the outcome of pregnancy through the development of neonatal lupus, a syndrome that is characterized by fetal and neonatal heart block and subcutaneous lupus lesions and the presence of 
antibodies to the cytoplasmic riboneucleoproteins Ro (SSA) and La (SSB). ${ }^{3,10}$

In this study, the aim was to analyse the pregnancy outcome in SLE patients as well as to identify the influence of disease activity on pregnancy outcome.

\section{Methods:}

We retrospectively reviewed pregnancy outcome in 27 SLE patients who were admitted in the fetomaternal medicine wing of the department of Obstetrics and Gynaecology, Bangabandhu Sheikh Mujib Medical University (BSMMU) during the period April 2007 to March 2011. The twenty eight consecutive pregnant patients with SLE either booked or non-booked cases were recruited. The booked cases were seen by obstetricians in the fetomaternal medicine outpatient department (OPD) and also by rheumatologist in their respective OPD for the disease condition. The non booked cases were referred from different hospitals or clinics or other obstetricians when some critical conditions arose. Of the twenty eight cases, one patient was treated conservatively following admission and then discharged but never came back for delivery and was excluded from the study. Of the twenty seven cases, two patients were diagnosed as a case of SLE for the first time during this pregnancy. One was diagnosed at her 26 weeks of gestation when she was admitted as a case of pregnancy with renal disease. She presented with skin rash, whole body swelling, high proteinuria with microscopic haematuria. The other patient was diagnosed at her 6 weeks of pregnancy with hypothyroidism when she presented with spotting, slight lower abdominal pain, swelling of both eyes and drooping of upper eyelid for 5 months.

Following admission, the patients were monitored carefully for disease activity and were managed by both rheumatologist and obstetricians. Eight of 27 (29.6\%) had active Lupus while nineteen of $27(70.3 \%)$ were in remission at presentation. SLE was considered to be active if two or more of the followings were present: i) acute synovitis detected on physical examination, ii) pleurisy or pericarditis with electrocardiographic or echocardiographic and/or radiological changes, iii) psychiatric or CNS manifestations, iv) thrombocytopenia $<90,000 / \mathrm{cu} \mathrm{mm}$, leucopenia $<4000 / \mathrm{cu} \mathrm{mm}$ or coombs $(+)$ ve haemolytic anaemia, v) active skin or mucus membrane lesions, vi) fever with infection and vii) active renal disease with abnormal urinalysis and / or protienuria and viii) low serum complement levels. Exacerbation or flare of disease was defined by the onset of new signs of disease in a previously normal organ system. ${ }^{1}$

The following laboratory tests were performed on all patients during the study period: complete blood count, erythrocyte sedimentation rate, blood glucose, serum urea, creatinine, uric acid and urine analysis. In addition levels of antinuclear antibody (ANA), anti double stranded DNA (ds DNA) antibody, antiphospholipid antibody and complement $\mathrm{C} 3$ and $\mathrm{C} 4$ were also determined.

In this study, gestational age of women was calculated from the last menstrual period, clinical examination and ultrasonography report. Fetal conditions were assessed by clinical examination, cardiotochography, USG and biophysical profile. The mode of delivery was decided on the basis of the condition of the mother as well as fetal condition. In most of the cases mode of delivery was by elective cesarean section. Immediately after delivery APGAR score and birth weight of the of the babies were noted. All the neonates were seen by neonatologists to exclude neonatal lupus.

For statistical analysis ' $z$ ' test of proportion was used for qualitative data, and student's ' $t$ ' test (unpaired) was used for quantitative data as sample size was small. Statistical significance was set at $\mathrm{P}<0.05$.

\section{Results:}

Mean age of the patients was 26.6 years (range 20-38 years). Most (85\%) belonged to age group 20-30 years and $15 \%$ belonged to $>30$ years age group. Regarding parity and gravidity, sixty seven percent of the patients were multigravid, where only $9(33 \%)$ were primigravida. Eight (29.6\%) had active lupus while 19 of 27 (70.3\%) were in remission at presentation. Amongst lupus antibodies, antinuclear antibody (ANA) was +ve in 22 $\%$, Anti ds DNA antibody in $18.5 \%$ and antiphospholipid antibody (APA) in $7.4 \%$ of the patients. Among the patients, 29.6\% (8/27) were on prednisolone, $55.5 \%(15 / 27)$ were on hydroxychloroquine and $18.5 \%(5 / 27)$ were on combined therapy that is on prednisolone as well as hydroxychloroquine therapy. Only one patient was having azathioprine in combination with prednisolone and hydroxychloroquine. Thirty three percent of the patients were on no such therapy (Table -I). 
Table-I

Patient characteristics during pregnancy

\begin{tabular}{cc}
\hline Characteristics & $\begin{array}{c}\text { Value } \\
(\mathrm{n}=27)\end{array}$ \\
\hline (mean+SD range)
\end{tabular}

a) Age at the time of pregnancy (yrs) 26.6(20-38) mean (range)

b) Duration of SLE (yrs)

4.4(0-12)

c) Main SLE manifestations

Renal disease

No. $(\%)$

$7(25.9 \%)$

$\begin{array}{ll}\text { Cutaneous lesions } & 2(7.4 \%) \\ \text { Haematological menifestations } & 2(7.4 \%)\end{array}$

d) Drugs taken during pregnancy

Prednisolone

$8(29.6 \%)$

Hydroxychloroquine

Aspirin

$15(55.5 \%)$

$2(7.4 \%)$

$1(3.7 \%)$

$5(18.5 \%)$

Combined therapy

No therapy

$9(33.3 \%)$

e) Active disease at conception

$8(29.6 \%)$

f) Laboratory findings at booking

Antinuclear antibody(ANA)

Anti ds DNA antibody

Antiphospholipid antibody

$6(22.2 \%)$

$5(18.5 \%)$

$2(7.4 \%)$

Effects of SLE on pregnancy: The duration of pregnancy was 34.8 weeks (range, 21-40 weeks). Of the pregnant SLE patients, $37.5 \%$ delivered preterm of which $66.6 \%$ of cases delivered before 34 weeks of gestation. Intrauterine death of fetus occurred in one (3.7\%) and spontaneous abortion occurred among three $(11.1 \%)$ of the SLE patients. Pregnancy induced hypertension was developed in $3.7 \%$ and severe preeclampsia in $11.1 \%$ of the patients (Table II ). There was no maternal mortality.

The mode of delivery was vaginal in $12.5 \%$ of the patients and rest $(87.5 \%)$ delivered by cesarean section. The indications for cesarean section were prematurity $(38 \%)$, severe preeclampsia $(14.2 \%)$, intrauterine growth retardation (38\%), twin pregnancy $(4.7 \%)$ and $\mathrm{H} / \mathrm{O}$ previous cesarean section $(33.3 \%)$

Table-II

Pregnancy complications in lupus patients $(n=25)$

\begin{tabular}{lcc}
\hline Pregnancy complications & No & $\%$ \\
\hline PIH & 1 & 3.7 \\
PE & 3 & 11.1 \\
Preterm delivery & 9 & 37.5 \\
IUGR & 8 & 33.3 \\
Spontaneous abortion & 3 & 11.1 \\
IUD & 1 & 3.7 \\
\hline
\end{tabular}

The mean neonatal birth weight was $2200 \mathrm{~g}$ (range 900$3100 \mathrm{~kg}$ ), mean APGAR score was 7.5 (range 6 -10) at 5 minute. Of live born infant, eight (33.3\%) were premature and eight $(33.3 \%)$ had suffered from intrauterine growth retardation. Twenty five percent $(6 / 24)$ of the neonates needs NICU admission (Table - III). None of the 24 neonates from these SLE mothers had neonatal lupus and there was no neonatal death.

Table-III

Neonatal outcome $(n=24)$

\begin{tabular}{lcc}
\hline Parameters & $\begin{array}{c}\text { No of neonates } \\
\text { No. }\end{array}$ & $\begin{array}{c}\text { Percentage } \\
(\%)\end{array}$ \\
\hline $\begin{array}{l}\text { Birth weight }(\mathrm{gm}) \\
<1000\end{array}$ & 1 & 4.16 \\
$\quad 1000-<2500$ & 10 & 41.6 \\
$\quad>2500$ & 13 & 54.16 \\
APGAR score & & \\
$\quad<7 / 5$ & 5 & 20.8 \\
$\quad>7 / 5$ & 19 & 79.16 \\
Prematurity & 8 & 33.3 \\
IUGR & 8 & 33.3 \\
Adm. In NICU & 6 & 25 \\
\hline
\end{tabular}

Patients who were in active disease state, most (62.5\%) of them delivered preterm. Preterm delivery rate was found significantly higher $(\mathrm{P}<0.05)$ in active lupus patients than lupus patients in remission. Conversely term delivery rate was found significantly higher $(\mathrm{P}<0.001)$ in remission group. In patients with active lupus, spontaneous abortion occurred in $25 \%$ and IUD occurred in $12.5 \%$, when in patients with remission there was no IUD and only $5.2 \%$ patients had spontaneous abortion, but the difference was not statistically significant between the two groups. Average gestational age at delivery was 33.6 wks and 37.2 wks for patients with active lupus and lupus in remission respectively and the difference was statistically significant $(\mathrm{P}<0.05)$. Mode of delivery was cesarean section in 62.5\% of the cases with active SLE. Of live born infant, average birth weight of the babies was found lower $(1.9 \mathrm{~kg})$ in patients with active SLE than in patients with remission $(2.3 \mathrm{~kg})$, but the difference was not statistically significant. Lupus flare developed in $25 \%$ of patients with active disease while in $5.2 \%$ of patients with remission (Table-IV). 
Table-IV

Pregnancy outcome: Active lupus vs lupus in remission $(n=27)$

\begin{tabular}{llllll}
\hline $\begin{array}{l}\text { Total pregnancy } \\
(\mathrm{n}=27)\end{array}$ & $\begin{array}{l}\text { Active lupus } \\
(\mathrm{n}=8)\end{array}$ & $\begin{array}{l}\text { Percentage } \\
(\%)\end{array}$ & $\begin{array}{l}\text { Lupus in remission } \\
(\mathrm{n}=19)\end{array}$ & $\begin{array}{l}\text { Percentage } \\
(\%)\end{array}$ & $\begin{array}{l}\text { P-value } \\
\text { Lupus flare(3) }\end{array}$ \\
Spontaneous abortion (3) & 2 & 25 & 1 & 5.2 & $>0.05$ \\
Intrauterine death (1) & 1 & 25 & 1 & 5.2 & $>0.05$ \\
Term delivery(15) & 1 & 12.5 & 0 & 0 & $>0.05$ \\
Preterm delivery(9) & 5 & 12.5 & 14 & 73.68 & $<0.001$ \\
Mode of NVD & 0 & 62.5 & 4 & 21.05 & $<0.05$ \\
Delivery C/S & 5 & 0 & 02 & 10.5 & $>0.05$ \\
Mean+ SD gestational age at & $33.6+2.7$ & 62.5 & 16 & 84.2 & $>0.05$ \\
delivery(wks) & & & $37.2+2.34$ & & $<0.05$ \\
Mean+ SD birth wt $(\mathrm{kg})$ & $1.9+.47$ & & & & \\
\hline
\end{tabular}

$P$ value reached from ' $z$ ' proportion test and unpaired students ' $t$ ' test

The outcome of 45 previous pregnancies among these SLE patients were also noted which included normal vaginal delivery in $15(41.6 \%)$, cesarean section in 7 (19.4\%), first trimester fetal loss in $13(36.1 \%)$, intrauterine death in $1(2.7 \%)$ and neonatal death in $2(5.7 \%)$.

The impact of pregnancy on SLE: Among SLE complications, 11.1\%(3/27) patient developed lupus flare, $26 \%$ (7/27) developed lupus nephritis and other $7.4 \%$ (2/ 27) developed skin rash (Table-V).

Table-V

Complications of SLE in pregnant lupus patient $(n=12)$

\begin{tabular}{lcc}
\hline SLE complication & $\begin{array}{c}\text { No of } \\
\text { patients }\end{array}$ & $\begin{array}{c}\text { Percentage } \\
(\%)\end{array}$ \\
\hline Lupus Flare & 3 & 11.1 \\
Lupus nephritis & 7 & 25.9 \\
Skin rash & 2 & 7.4 \\
\hline
\end{tabular}

\section{Discussion:}

Pregnancy in lupus was considered highly risky because of high flare up rate, increased frequency of fetal loss, premature births, neonatal lupus and perinatal mortality.

During the study period (April 2007 - March 2011), twenty seven pregnant SLE patients were admitted in the department of Obstetrics and Gynaecology, BSMMU, when total obstetric patients admitted were 7064 . The ratio of the SLE patients admitted was 3.8/1000.
In this study, $29.6 \%$ of patients had active SLE while $70.3 \%$ were in remission at presentation. Tan LK et al ${ }^{14}$ showed $96.2 \%$ [26/27] patient had lupus in remission at booking. Porkodi et $\mathrm{al}^{2}$ found $27.3 \%$ had active lupus and $72.7 \%$ were at remission at conception. Cortes-Hernandez et $\mathrm{al}^{3}$ showed seven $(6.7 \%)$ patients had active lupus at conception.

The mean age of the study subjects were 26.6 years (range, 20-38 years) which corresponded to the study done by Porkodi $\mathrm{al}^{2}$ where mean age was 25 years (range, 19-34 years ) and Wong et $\mathrm{al}^{15}$ showed that mean age of the study patients was about 27.7 years (range, 23-37 years).

In this study, $33.3 \%(9 / 27)$ of the pregnancies were the first pregnancy for the patients, $18.5 \%(5 / 27)$ were the second, $14.8 \%$ (4/27) were the third and $33.3 \%$ (9/27) were the fourth or more pregnancies. In a study done by Wong et al ${ }^{15}$ showed $41 \%(7 / 24)$ was the first pregnancy, $47 \%$ $(8 / 24)$ was the second and $29.4 \%$ was the third pregnancy.

Tan LK et $\mathrm{al}^{14}$ reported in their study that most of the patients were nulliparous when this series showed $44.4 \%$ of the patients were nulliparous.

In this study, the mean gestational age at delivery was 34.8 weeks (range, $21-40 \mathrm{wks}$ ) and $33.3 \%$ of the patients delivered preterm. Wong $\mathrm{CH}$ et $\mathrm{al}^{15}$ showed that the mean gestational age at delivery was 34.3 weeks (range, 17-41 weeks) when preterm delivery occurred in $37.5 \%$ of cases. Cortes-Hernandez et $\mathrm{al}^{3}$ showed in his study that preterm delivery rate was $28 \%$. Georgiou et $\mathrm{al}^{1}$ showed sixty one percent of SLE pregnancies were delivered at term where 
only $5 \%$ had preterm delivery. Hence our study corresponded more with Wong $\mathrm{CH}$ et a ${ }^{15}$.

In this study, mode of delivery was vaginal in $12.5 \%$ (3/24) of the cases and cesarean section rate was $87.5 \%$, where as Wong $\mathrm{CH}$ et $\mathrm{al}^{15}$ showed vaginal delivery rate was $54.2 \%$ and $\mathrm{C} / \mathrm{S}$ rate was $45.8 \%$. This differences might be due to lack of availability in the modern obstetric care along with differences in the patient selection where more patients were in active disease state associated with other high risk factors such as severe preeclampsia, IUGR and twin pregnancy.

In this study, mean neonatal birth weight of the live born infant was $2200 \mathrm{~g}$ (range, 900-3100 g), mean APGAR score was 7.9 at 5 minute and $33.3 \%(8 / 24)$ of the cases showed IUGR. Twenty five percent (6/24) of the neonates needed NICU admission. None of the 24 neonates from these SLE mothers had neonatal lupus and there was no neonatal death.

Wong $\mathrm{CH}$ et $\mathrm{al}^{15}$ showed that the average birth weight of the neonate was $2179 \mathrm{~g}$, APGAR score was 9 at 5 minute, IUGR was found in $20.8 \%$ of cases and there was one baby (among 24 pregnancies) born with congenital heart block. Tan LK et $\mathrm{al}^{14}$ in their study found mean birth weight was $3047 \mathrm{~g}$, APGAR score was 9 at 5 minute and there was no case of congenital heart block. Cortes-Hernandez et al ${ }^{3}$ showed IUGR in $35 \%$ of cases and one case of congenital heart block among 68 live births. Georgiou et $\mathrm{al}^{1}$ in their study showed, none of the 39 neonates had neonatal lupus but one intrauterine fetal death.

In this study prematurity rate was high, about $37.5 \%$, when most of these preterm deliveries $(55.5 \%)$ occurred in patients with active disease (Table - IV). Wong $\mathrm{CH}$ et al ${ }^{15}$ found high rate of prematurity associated with lupus pregnancy, when he did not find any correlation with prematurity and SLE activity. In contrast, Minz et al ${ }^{10}$ and Petri ${ }^{16}$ found a significant correlation between SLE activity and prematurity. Georgiou et al ${ }^{1}$ also observed reduced number of term deliveries among patients with active SLE.

In this study, there was $14.8 \%$ (4/27) of fetal loss of which there were three spontaneous abortions and one intrauterine death and most (3/4) of these occurred in active disease state (Table -IV).

A fetal loss of $41 \%$ was reported by Porkodi et $\mathrm{al}^{2}$ which may be due to increased number of patients with active disease at the time of conception. Cortes-Hernandez et $\mathrm{al}^{3}$ showed high rate of fetal loss about $28 \%$ which was due to prematurity, spontaneous abortion, and intrauterine fetal death. Several other studies have found frequency of fetal loss to vary between 11 and $24 \%{ }^{18,19,21,22}$. These differences may be due to many factors, such as patient selection, fetal monitoring, availability of treatment facilities and the use of modern obstetric care.

In this study, pregnancy induced hypertension (PIH) was observed among 3.7\% (1/27), severe preeclampsia in $11.1 \%$ (3/27) and GDM in 14.8\% (4/27) as obstetric complications. In different studies, Porkodi et $\mathrm{al}^{2}$ showed PIH in $4.5 \%$ of cases. Wong $\mathrm{CH}$ et al ${ }^{15}$ found preeclampsia in $12.5 \%$ of cases and Tan LK et al ${ }^{14}$ observed GDM in $14.8 \%$ of cases which corresponded more or less with this study.

As SLE complications, lupus flare was noticed in 11.1\% (3/27) of cases, lupus nephritis was observed in $25.9 \%$ (7/ $27)$ and skin rash in $7.4 \%(2 / 27)$ of cases of this series.

Study done by Georgiou et $\mathrm{al}^{1}$ showed flare up rate $13.5 \%$, Wong $\mathrm{CH}$ et $\mathrm{al}^{15}$ observed flare up rate $19.2 \%$ which correlates well with our study. Porkodi et $\mathrm{a}^{2}$ found flare up rate $45.5 \%$ and Song $\mathrm{YJ}$ et $\mathrm{al}^{23}$ found flare up rate in $62.5 \%$ of the cases when Cortes-Hernandez et $\mathrm{al}^{3}$ observed $33.3 \%$ had disease flare up. Differences in the study results may be due to differences in the composition of patient cohorts and the use of non-standardized definitions of lupus flare.

Most of the prospective studies showed lupus nephritis only in minority of the patients $(10 \%)^{1}$. In this study lupus nephritis was observed in $26 \%$ of cases. The differences in study results may be due to differences in selection of patient composition.

Cutaneous or articular manifestations are the most common clinical findings of SLE during pregnancy ${ }^{13}$. Georgiou et $\mathrm{al}^{1}$ found arthralgia, arthritis, skin lesions and fever were the most prominent symptoms in pregnant SLE patients, but there was no acute synovitis. In this series of SLE patients, however, no acute synovitis was observed, only $7.4 \%$ patients showed skin lesions (Illustration 1).

In this study there was no maternal death. Porkodi et $\mathrm{al}^{2}$ showed $9 \%$ maternal death and Song YJ et $\mathrm{al}^{23}$ found $4.1 \%$ maternal deaths in their study which may be due to more patients were with active disease at the time of conception. Wong $\mathrm{CH}$ et al ${ }^{15}$ as well as Tan $\mathrm{LK}^{14}$ observed no maternal mortality in their study which correlates with this study.

\section{Conclusion:}

Pregnancy is relatively safe in woman with SLE in remission but should be considered as high risk in terms of fetal loss and spontaneous abortion. Disease activity influences the term delivery and total fetal loss. In order to 
achieve a better outcome of lupus pregnancy, it is essential that SLE should go into remission before conception, to control disease activity with proper treatment and close monitoring of the patients during pregnancy, thereby improving fetal survival and reducing lupus flare rates.

\section{References:}

1. Georgiou P E, Politi E N, Katsrimbi P, Sakka V, Drosos A A. Outcome of Lupus pregnancy: A controlled study. Rheumatology 2000; 39: 1014-1019

2. Porkodi R, Manimegalai N, Balameena S, Vasanthy N, Madavan $\mathrm{R}$, Rajendraran CP. Outcome of pregnancy in Lupus. J Indian Rheumatol Assoc 2005; 13: 83-85

3. Cortes-Hernandez J, Ordi-Ros J, Paredes F, Casellas M, Castillo F, Vilardell-Tarres M. Clinical predictors of fetal and maternal outcome in systemic lupus erythemetosus: A prospective Study of 103 pregnancies. Rheumatology 2000; 41: 643-650.

4. Petri M, Howard D, Repke J. Frequency of lupus lares in pregnancy: the Hopkins Lupus Pregnancy Centre experience. Arthritis Rheum1991:34:1538-45.

5. Zulman J C, Talal N,Hoffman G S, Epstien W V. Problems associated with the management of pregnancies in patients with systemic lupus erythematosus. J Rheumatol 1980; 7:3749 .

6. Ruiz-Irastorza G, Lima F, Alves J, et al. Increased rate of lupus flare during pregnancy and the puerperium. Br J Rheumatol $1996 ; 35: 133-8$

7. Wong K L, Chan F Y, Lee C P. Outcome of pregnancy in patients with systemic lupus erythematosus. Arch Intern Med 1991; 151: 269-73.

8. Lockshin M D, Reinitz E, Druzin M S, Dr Syeda Sayeeda et al. Lupus Pregnancy: Case control Prospective study demonstrating absence of lupus exacerbation during or after pregnancy. Am J Med 1984; 77: 893-8.

9. Meeehan R T, Dorsey J K. Pregnancy among patients with systemic lupus erythematosus receiving immunosuppressive therapy.J Rheumatol 1987;14: 252-8

10. Mintz G, Niz J, Gutierrez G, Garcia Alonso A, Karchmer S. Prospective study of pregnancy in systemic lupus erythematosus: Result of a multidisciplinary approach. J Rheumatol 1986; 13: 732-9.
11. Urowitz M, Gladman D, Farewell V, Stewart J, McDonald J. Lupus and pregnancy studies. Arthritis Rheum 1993; 36:13927 .

12. Carmona F, Font J, Cervera R, Munoz F, Cararach V, Balasch J. Obstetrical outcome of pregnancy in patients with systemic lupus erythematosus. A study of 60 cases. Eur J Obstet Gynaecol 1999; 83:137-42.

13. Khamashta M A, Ruiz-Irastroza G, Hughes G R. Systemic lupus erythematosus flares during pregnancy. Rheum Dis Clin North Am 1997; 23:15-30

14. Tan LK, Tan HK, Lee CT, Tan AS. Outcome of pregnancy in Asian women with systemic lupus erythematosus: experience of a single perinatal centre in Singapore. Ann Acad Med Singapore.2000; 31(3): 290-5.

15. Wong CH, Chen TL, Lee CS, Lin CJ, Chen CP. Outcome of pregnancy in patients with Systemic Lupus Erythematosus. Taiwanese J Obstet Gynaecol. 2006 June; 45(2): 120-3.

16. Petri M. Systemic lupus erythematosus and pregnancy. Rheum Dis Clin North Am. 1994; 20: 87-118.

17. Lockshin M D. Pregnancy does not cause systemic lupus erythematosus to worsen. Arthitis Rheum 1989; 32:665-70.

18. Lockshin MD, Reinitz E, Druzin ML, Murrman M, Estes D. Lupus pregnancy case-control prospective study demonstrate absence of lupus exacerbation during or after pregnancy. Am J Med 1984; 77: 893-8.

19. Nossent HC, Swaak TJG. Systemic lupus erythematosus. VI: Analysis of the interrelationship with pregnancy. J Rheumatol $1990 ; 17: 771-6$.

20. Song YJ, Liu JT, Jhao Y. Predictors of maternal and lupus erythematosus flares during pregnancy. Rheum Dis Clin North Am 1997; 23:15-30.

21. Fraga A, Mintz G, Orozeo J. Sterility and fertility rates, fetal wastage and maternal morbidityin systemic lupus erythematosus. J Rheumatol 1974; 1:293-8.

22. Tseng C E, Buyon J P. Neonatal lupus syndrome. Rheum Dis Clin North Am 1997; 23: 31-54

23. Song YJ, Liu JT, Jhao Y. Predictors of maternal and fetal outcome in systemic lupus erythematosus: a retrospective study of 94 cases. Zhonngua Nel ke Za Zhi 2008; 47(12): $1008-11$ 